\title{
(CRI)AÇÕES NA INFÂNCIA POR INTERMÉDIO DA PRÁTICA DOCENTE COM OS PROCEDIMENTOS DO DESENHO
}

\author{
Marilani Martins dos Santos Ghiraldini ${ }^{1}$, Maria Luzia da Silva Santana ${ }^{2}$, \\ Marcelo Máximo Purificação ${ }^{3}$
}

Resumo: O objetivo desse artigo é descrever a (cri)ação de crianças, por intermédio dos procedimentos de ensino denominados e do Desenho, como um dos elementos constituintes da prática pedagógica. Para isso, tal procedimento foi utilizada para trabalhar as temáticas: esquema corporal, família e escola numa sala de educação infantil a partir de quatro momentos. No decorrer do processo de aplicação dessa metodologia, que incluiu a ação de desenhar, ocorreu a observação das crianças sendo registradas suas ações e falas no diário de bordo. Foram analisados os desenhos de duas crianças, aqui denominadas de Maria e Davi, que evidenciaram elementos constituintes do contexto familiar e escolar. A Metodologia do Desenho foi elemento favorecedor do processo de ensino-aprendizagem e propulsor da aprendizagem e desenvolvimento das crianças.

Palavras-chave: (Cri)ações. Educação. Infância. Procedimentos do desenho. Prática pedagógica.

1 Pedagoga pelo Centro Universitário de Mineiros. Especialista em Ludopedagogia e Psicopedagogia Institucional e Clínica pela FAVENI. Pesquisadora no Núcelo de Estudos, Pesquisas e Extensão Multidisciplinar - NEPEM /UNIFIMES e professora no Colégio Ágape-GO.

2 Doutoranda e Mestra em Psicologia (Universidade Católica de Brasília- UCB). Especialista em Educação e Promoção da Saúde (Universidade de Brasília - UNB) e em Psicologia Social (Universidade Estadual de Santa Cruz-UESC). Psicóloga (Centro de Ciências da Saúde da Universidade Federal do Recôncavo da Bahia- UFRB). Licenciatura Plena em História (Universidade do Estado da Bahia -UNEB) e em Pedagogia (Faculdades Alfredo Nasser - UNIFAN). Professora Assistente, com Dedicação Exclusiva, na Universidade Federal do Mato Grosso do Sul - UFMS. Foi Professora Adjunta no Centro Universitário de Mineiros-GO - UNIFIMES.

3 Pós-Doutor Júnior em Educação pela Faculdade de Psicologia e Educação da Universidade de Coimbra (UC-PO). Doutor em Ciências da Religião (Pontifícia Universidade Católica de Goiás- PUC-GO). Mestre em Educação Comunitária - Infância e Juventude (Universidade Federal do Rio Grande do Sul - FEST/UFRGS). Mestre em Ciências Educacional - UEP (2007). Possui especialização em Docência do Ensino Superior, Gestão e Orientação Educacional e Educação Matemática. Licenciatura em Filosofia, Pedagogia, Matemática e Bacharelado em Teologia. Atualmente, é Professor na SEDUCEGoiás e Professor Titular no Centro Universitário de Mineiros-GO - UNIFIMES e na Faculdade FAMA. Professor Associado da ANPED - Associação Nacional de Pós-Graduação e Pesquisa em Educação (no Brasil) e na AFIRSE - Associação Francofone de Pesquisa Científica em Educação (em Portugal). Coordenador do Núcelo de Estudos, Pesquisas e Extensão Multidisciplinar - NEPEM / UNIFIMES e líder do Grupo de Estudo e Pesquisa em Psicologia, Neurociências e Educação (GEP - PNEdu). 


\title{
CRE (ATIONS) CHILDHOOD THROUGH THE TEACHING PRACTICE WITH THE PROCEDURES OF THE DRAWING
}

\begin{abstract}
The aim of this article is to describe the (cri) share of children through educational procedures called the design methodology, as one of the constituent elements of teaching practice For this, this procedure was used to work the themes: body image, family and school in a kindergarten room from four times. During the application of this methodology process, which included the action to draw, was the observation of children being registered their actions and speeches in the logbook. drawings of two children were analyzed, here called Mary and David, who showed elements of the family and school context. The design methodology was favoring element of the teaching-learning process and driver of learning and development of children.
\end{abstract}

Keywords: (Cre)ations. Education. Childhood. Drawing Procedures. Teaching Practice.

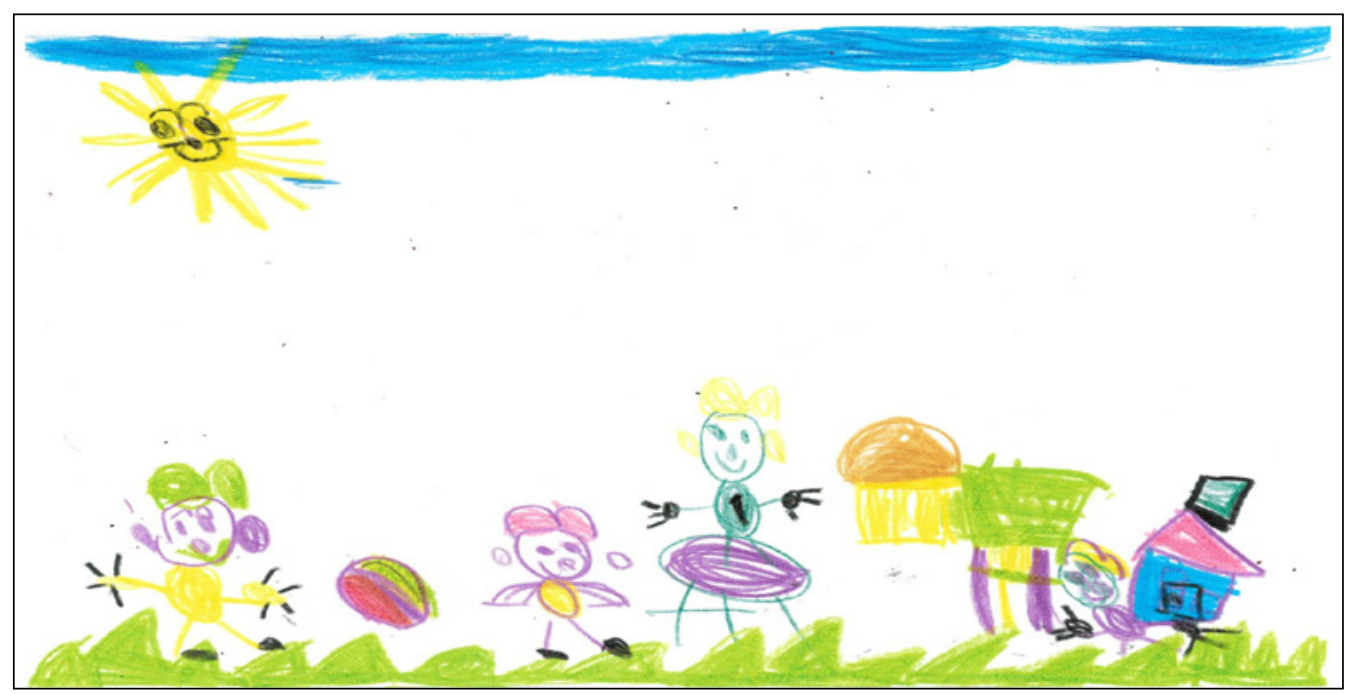

Desenho construído por Davi de 5 anos, em 2015.

\section{INTRODUÇÃO}

$\mathrm{O}$ ato de desenhar está ligado às atividades relacionadas à expressão artística; mas tal ato expressivo se situa para além das convenções estéticas e das escolas de artes. Haja vista a presença de desenhos em cavernas e monumentos pré-históricos, com as mais variadas finalidades. A criança evolui graficamente, quando se apropria desse sistema de representação gráfica e adquire a maior capacidade de representar os seres humanos, as figuras geométricas e outros sinais gráficos (SIMAS, 2011).

O desenho é uma das linguagens que "poucos adultos conseguem perceber o quanto o desenho infantil pode ser revelador do grau de maturidade, do equilíbrio emocional e afetivo, bem como do desenvolvimento motor e cognitivo da criança" 
(ALEXANDROFF, 2010, p. 23). O desenho é uma linguagem que a criança utiliza muito antes da escrita, para muitas finalidades: comunicar ideias para outras pessoas, representar situações, enfeitar e brincar. Do mesmo modo que outras atividades lúdicas, o desenho, neste caso, nada mais é que o pensamento da criança transcrito no papel (MOREIRA, 1999). Na linha dessas ideias Meredieu (2004, p. 2-4), pontua que os primeiros estudos e pesquisas com interesse no desenho data-se do final do século XIX.

Vygotsky (1987), apontou quatro fases para o desenho infantil: 1) Desenho-simbólico em que a criança já possui capacidade de representar os seres humanos, mas com formatos diferentes do real. 2) Desenho simbólico-formalista é a fase na qual já se percebe maior elaboração dos traços e formas no desenho infantil. 3) Desenho formalista veraz é a fase que mais se aproxima do real e tem mais presença do simbolismo. 4) Formalista plástica a representação do desenho deixa de ser uma atividade com fim em si mesmo e passa a ser um trabalho criador.

Já Piaget (1978) descreve as seguintes fases do desenho: 1) Garatuja - que faz parte da fase sensória motora e parte da pré-operacional e incluem, a garatuja desordenada - onde os movimentos são amplos e desordenados, e não existe preocupação com a preservação dos traços e a garatuja ordenada - os movimentos surgem com traços longitudinais e circulares sendo que a figura humana aparece de maneira imaginária. 2) Pré-esquematismo - que aparece na segunda metade da fase pré-operatória, prolongandose geralmente até os sete anos quando acontece a relação entre desenho, pensamento e realidade. 3) Esquematismo - faz parte da fase das operações concretas, dentro dos esquemas representativos, e é nesta fase que o desenho começa a estabelecer maneiras diferenciadas para cada categoria de objeto. 4) Realismo - surgem no final das operações concretas, quando há maior consciência do sexo; começa uma autocrítica pronunciada e, geralmente, nessa etapa, os desenhos apresentam roupas diferenciadas para cada um dos sexos. 5) Pseudonaturalismo - faz parte da fase das operações abstratas, sendo considerada o fim da arte como atividade espontânea.

Olhando pelo prisma da autora Meredieu (1974), o desenho infantil estrutura em etapas de desenvolvimento e seu significado se materializa em pequenos atos tais como: "O prazer do gesto, o prazer da inscrição, do gesto ao traço (conquista de uma língua), do traço ao signo e a construção do espaço (da coisa em si para a convenção)".

O desenho é um dos elementos que contribuem com o processo de alfabetização, influencia a aprendizagem e o desenvolvimento da criança. As informações contidas no desenho possibilitam ao profissional da educação contribuições para entender aspectos do desenvolvimento psicossocial, emocional, cognitivo e da personalidade da criança (LOPES, 2010). Por outro lado, o desenho infantil também pode transmitir inúmeros significados que podem não ser identificados imediatamente pelo profissional que orienta a criança, fato que instiga o desenvolvimento de estudos sobre práticas pedagógicas na Educação Infantil que estimulem o ato de desenhar.

Considerando esses elementos foi desenvolvida e realizada a prática pedagógica denominada de Procedimentos de Ensino e do Desenho, que possibilitou analisar a 
produção de duas crianças: uma com quatro anos de idade, do sexo feminino, com nome fictício de Maria e outra do sexo masculino, com quatro anos, com nome fictício de Davi. Nesse artigo, o objetivo é descrever a (cri)ação das crianças, por meio dos procedimentos de ensino da citada Metodologia entendendo-a como um dos elementos constituintes da prática pedagógica. Mais esclarecimentos da ação educativa empregada, os procedimentos realizados durante a aplicação da Metodologia foram descritos na seção seguinte.

\section{METODOLOGIA}

Como o próprio nome deste artigo sinaliza, os procedimentos metodológicos adotados foram denominados de Metodologia do Desenho e aplicados numa turma de educação infantil, Jardim I com crianças de idades entre quatro e cinco anos, de uma instituição da rede privada localizada na região Sudoeste do Estado de Goiás, cuja missão declarada é "servir com excelência, comprometimento e amor, viabilizando o crescimento pessoal e humano dos alunos".

O Procedimento de Análise do Desenho se constitui como elemento da prática educativa baseada em atividades lúdicas, focalizando o desenho como o principal recurso. Durante esse processo foram realizados quatro momentos, com duração de aproximadamente uma hora e 30 minutos cada um, quando foram trabalhadas as temáticas: esquema corporal, família e escola. Esses temas, depois de explorados pela professora, foram desenhados pelas crianças, com observação de seu comportamento no decorrer dos momentos e registros de suas ações principais no diário de bordo. Os procedimentos ocorreram conforme descrito abaixo:

No primeiro momento a temática trabalhada foi esquema corporal. Para isso, foram utilizados os bonecos de tecido, considerados pela turma como seus novos amigos; eles foram manuseados com a finalidade de explorar o reconhecimento das partes do corpo, com a montagem e desmontagem dos mesmos com a mediação da pesquisadora. As crianças foram, então, orientadas a registarem a temática apresentada mediante o desenho.

No segundo momento foi trabalhada a temática família, mediante a contação de histórias com fantoches. No cantinho da literatura a professora apresentou para as crianças vários livros com o contexto de família, que puderam observar a diversidade de famílias existentes, e escolheram a história dos três ursos para ouvi-la. Elas desenharam a temática e na devolutiva do desenho a professora realizou as seguintes perguntas: O que desenhou? Quem são essas pessoas? Como se chamam? Após os relatos das crianças, as informações foram registradas no diário de bordo.

No terceiro momento foi trabalhada a temática ambiente escolar com a apresentação de imagens da escola na roda de conversa e o passeio na própria escola; posteriormente, as crianças desenharam o seu contexto escolar. No quarto momento a temática trabalhada 
foi autorretrato. Numa roda de conversa com as crianças, foram apresentados objetos como: imagens de bichos com os filhotes, máscaras, fantoches, rótulos com desenhos de famílias, crianças na escola sendo pedido a cada criança para escolher uma das imagens e contar uma historinha sobre ela. Após a dinâmica, houve um espaço para escuta das crianças e, na sequência, elas fizeram os desenhos. As informações registradas possibilitaram apresentar o caso de duas crianças, a partir das categorias contexto educativo, família e constituição do eu que foram apresentadas e discutidas na seção seguinte.

\section{RESULTADO E DISCUSSÃO}

Os resultados apresentados, mediante as produções de Maria e de Davi demonstraram que o desenho infantil não é somente uma forma de expressão, mas se constitui como uma ferramenta de aprendizagem e desenvolvimento, além de se constituírem como uma primeira escrita que possibilitou emitir as emoções, vivências e contextos das crianças.

\section{1 (Cri)ação e análises do desenho de maria}

Maria tinha, na ocasião da aplicação da Metodologia, quatro anos e nove meses de idade, cor branca, classe social média, com $99 \mathrm{~cm}$ de altura e pesava 14,8 kg. Sua família era composta por pai, mãe e duas filhas.

\subsubsection{Maria e o Contexto Educativo Formal}

Maria começou a frequentar o Colégio desde seu primeiro ano de idade, no maternal, período vespertino, sendo que nunca mudou esse contexto escolar até a realização dessa pesquisa. Além das atividades de sala de aula, no decorrer de seu turno, Maria participava de outras aulas tais como: educação física, dança recreativa, inglês e leitura.

A adaptação escolar de Maria, segundo as observações da professora, foi considerada adequada. Inicialmente, demonstrou ansiedade para conhecer a nova professora e os novos amigos, ou seja, para explorar e interagir com as pessoas que fazem parte do seu contexto de convivência escolar.

Para Piaget (1973) sem maturação suficiente não há desenvolvimento; assim, o conhecimento não é imanente nem ao sujeito, nem tampouco aos objetos, mas é construído mediante a interação entre ambos. $O$ processo de adaptação da criança ao novo mundo da escola é fundamental para sua formação, porque é nesse ambiente que ela desenvolve várias habilidades. No caso, a criança Maria, já está adaptada a seu ambiente escolar e, por meio da apresentação de seu desenho, é possível verificar isso, 
já que ela desenhou uma faixa de pedestre, localizada em frente ao colégio, com uma escada que dá acesso à entrada, e representou a sua chegada nesse espaço (Desenho I).

Desenho I - O contexto escolar de Maria

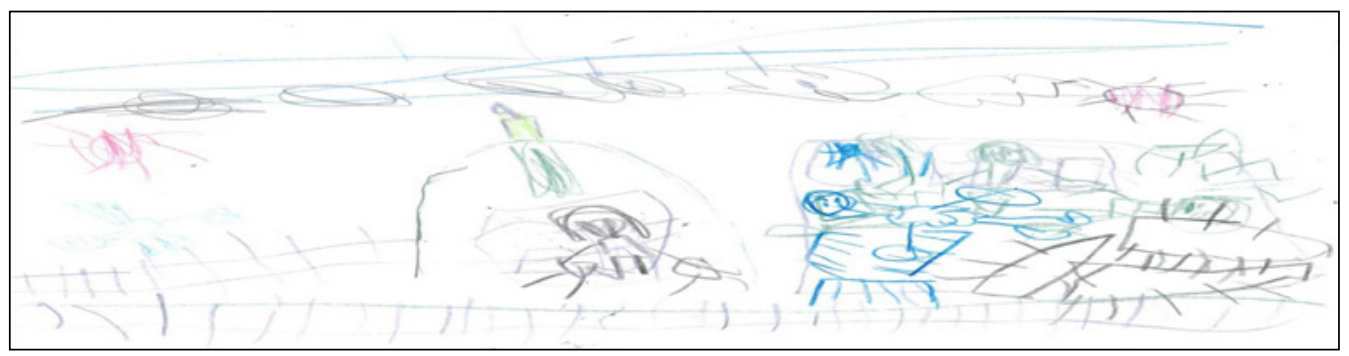

Neste desenho, Maria apresentou sua sala de aula, com todas as cadeiras dos colegas, mesas, armários e sua professora ao centro; apesar de existirem outros espaços, os que prenderam sua atenção foram esses. $\mathrm{O}$ espaço não é algo vazio, ele é sempre construído, modificado, (re)significado a partir das relações que se estabelecem dos sujeitos entre si ou do sujeito consigo mesmo (LIMA, 1989), sendo possível sugerir que a sala de aula e a entrada na escola são espaços marcantes para Maria.

De acordo com Lima (1989), as crianças interagem com os espaços escolares, criando neles ambientes e dando-lhes significados. Assim, é possível sugerir que a sala de aula é um espaço de aprendizagem e de trocas para Maria, que envolve o conhecimento científico e outros elementos constituintes do um ser humano. A partir de observações realizadas no seu cotidiano de sala de aula, é possível caracterizá-la como uma criança tranquila, alegre e dinâmica, que interage com os colegas e funcionários, sendo carinhosa, comunicativa e prestativa.

Natividade, Coutinho e Zanella (2008), afirmam que o desenho infantil requer também que se reflita sobre linguagem, imaginação, percepção, memória, emoção, significação, ou seja, tentar compreender os processos psicológicos envolvidos/ constituídos no processo de desenhar, sendo que a produção dessa atividade - o desenho - que não pode ser analisada de forma isolada, visto serem interdependentes. Quando a criança desenha o que entende da realidade, ela objetiva a sua subjetividade, a realidade tal como a significa, significação essa constituída a partir dos muitos outros sujeitos com os quais convive/dialoga e dos sentidos que circulam nesses contextos, o que leva a compreender que o desenho expressa não apenas fantasia (VYGOTSKI, 1989).

No contexto de sala de aula, observou-se que Maria é uma criança que brinca com diferentes objetos, como caixinhas de fósforos, colher de plástico, potinhos de iogurte. Tudo que está à sua volta se transforma em brinquedos; essa criativa e envolvimento de Maria também estão presentes nos seus desenhos. Pillar (1996), afirma que a criança desenha pelo prazer de produzir, de marcar uma superfície, sem ter a intenção de representar, simbolizar algo com essa atividade. Afirma ainda que, somente após os 
estágios da exploração da possibilidade de realizar marcas do material gráfico é que a criança começa a relacionar seus traços como meio físico ou psíquico.

\subsubsection{Maria nos aspectos familiares}

A atenção e os afetos recebidos na infância, tanto dos pais quanto dos professores e demais adultos com os quais a criança convive, ajudam-na a desenvolver sua concepção de mundo. O desenho de Maria possibilita observar tais elementos (Desenho II).

Desenho II - Maria em férias com a família

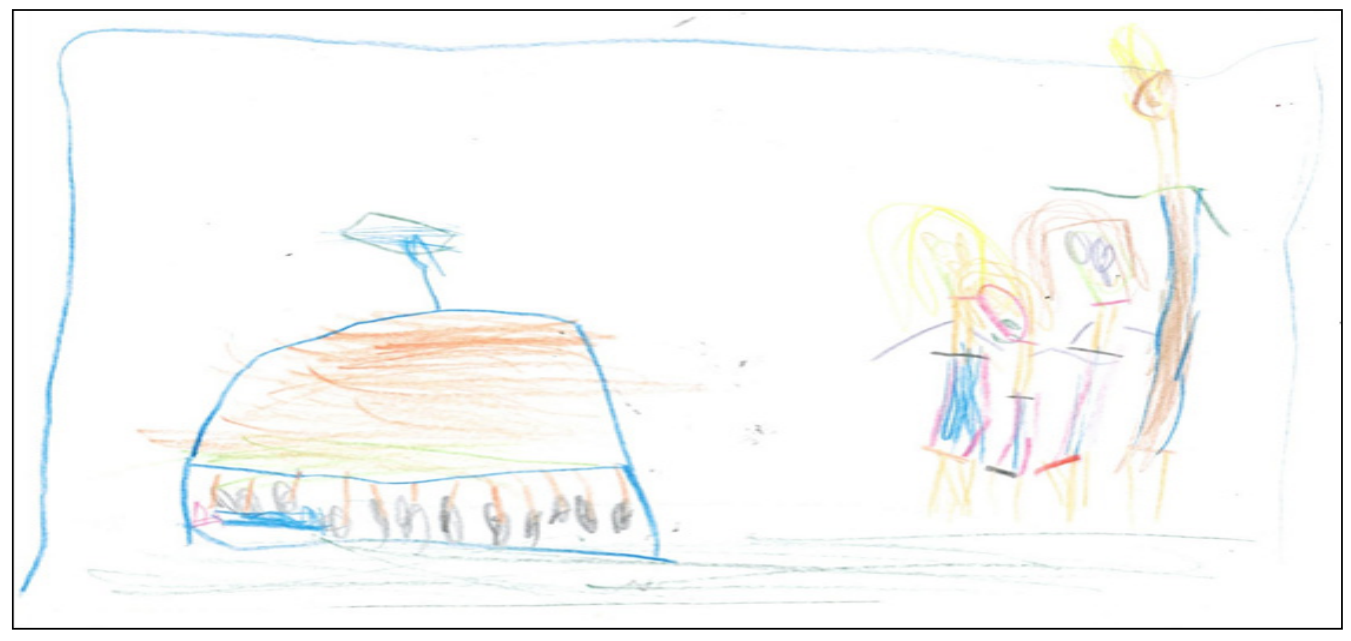

O desenho II foi construído depois de se trabalhar a temática família em sala de aula; nele, Maria representou a constituição de sua família. Vygotsky (2003) lembra que os desenhos são considerados signos empregados pela criança e constituídos a partir da interação social, sendo um instrumento de representação que vai sendo substituído no decorrer do tempo. A observação de Maria enquanto realizava o desenho - incluindo a atenção para seu corpo, o seu olhar, a mudança de expressão no rosto e sua movimentação - possibilitou compreender aspectos de sua aprendizagem e do seu desenvolvimento. É preciso considerar, diante de uma criança que desenha, aquilo que ela pretende fazer: contar-nos uma história e nada menos que uma história, mas devemos também reconhecer, nesta intenção, os múltiplos caminhos de que ela se serve para exprimir aos outros a marcha dos seus desejos de seus conflitos e receios (MOREIRA, 1995).

No desenho da família de Maria é possível observar que ela ocupou totalmente a folha com traços suaves, com o céu e o chão definidos. A família, durante a realização do passeio está fora da cabana, ela encontra-se junto à mãe, vestida da mesma forma e num tamanho menor. O desenho é explicado por Vygotsky (1989) como um estágio preliminar do desenvolvimento da escrita, em cuja base está a linguagem falada; nele, a criança expressa o seu pensamento e conhece. 
Maria se representou perto de sua mãe, sugerindo ser este o membro familiar mais próximo. A partir da família representada, observa-se que a criança revela um conceito definido sobre a figura humana, trazendo elementos constitutivos do corpo biológico das pessoas e, no decorrer da realização do desenho, ela demonstrou cuidado, criatividade e curiosidade nos tracejados e detalhes de seus familiares. Maria traz e representa um momento que a marcou, revelando elementos de sua história, de momentos passados, articulados aos seus sentimentos e imaginação.

A criança, ao desenhar, faz suposições, reúne seus conhecimentos, faz relações, traz as situações vividas de outra maneira, sendo que esse processo, por volta de cinco anos já é mais bem identificado (RABELLO, 2013). Maria é a caçula numa família de duas filhas; tal aspecto é revelado por intermédio do seu tamanho representado no desenho, que - ao lado esquerdo - apresentou sua cabana e - do lado direito - a sua família, na qual ela é a menor dos membros. A sua figura paterna ocupa um lugar de destaque, ao ser representada como o mais alto entre os membros.

Para a criança o desenho é uma expressão de mundo e nunca uma simples imitação ou cópia fiel da realidade; ela desenha conforme o modelo interior, a representação mental que possui do objeto a ser desenhado. O desenvolvimento infantil é como um jogo, visto que a criança se desenvolve e se modifica conforme a faixa etária; o desenho acompanha essa evolução (ZOPELARI, 2007).

A partir de Vygotsky (1998) é possível compreender o desenho infantil considerando o contexto histórico e cultural no qual a criança está inserida, sendo este marcado pelas condições que lhe são disponibilizadas. Assim, o desenho da criança não é algo inato, natural e espontâneo, isto é, não surge por si mesmo da criação artística infantil, mas a criação depende dos instrumentos e signos presentes no contexto de convívio da criança. Nesse sentido, os elementos do contexto de convivência de Maria são apresentados, a exemplo do seu passeio com a família na cabana, representando elementos constitutivos e/ou presentes na sua relação familiar.

Os detalhes do desenho de Maria sugerem afetos positivos de sua relação familiar, representados por elementos constituintes da estruturação de seu ser, de sua personalidade e do seu desenvolvimento psicomotor. Numa perspectiva interpretativa e apoiado em Santos (2013) é possível observar a percepção de uma estrutura emocional estável e equilibrada, apoiada numa segurança familiar expressa por meio do colorido geral do desenho e das figuras parentais desenhadas de uma forma harmoniosa. Assim, a presença de detalhes agradáveis de teor positivo (a família unida de Maria) sugere um ambiente familiar harmonioso, onde ela está no plano mais abaixo dos pais, sua mãe está mais próxima por razões eventualmente relacionadas com o apoio e cuidados maternos, e o pai está mais próximo da filha mais velha assumindo uma posição mais elevada, refletindo a eventual autoridade sociofamiliar que lhe é conferida.

O desenho como possibilidade de brincar, de falar, de registrar, marca o desenvolvimento da infância, porém, em cada estágio, o desenho assume um caráter próprio, variando, inclusive, muito pouco de cultura para cultura (SIO, 2012). 
Considera-se que, depois de ser trabalhada a temática família, Maria - em seu desenho - apresentou e ampliou ideias oriundas do seu cotidiano sobre a constituição familiar.

Mediante a Metodologia do Desenho houve um trabalhado planejado e intencional na sala de aula sem desconsiderar as informações do dia a dia de Maria sobre a família; assim, o conhecimento do cotidiano ganhou um olhar científico. Deste modo, Maria foi colocada como sujeito ativo na constituição do conceito de família a partir da mediação da professora, chegando a uma definição "possível" naquele momento para família, que para Santos (2013) é uma associação de pessoas que escolhem conviver por razões afetivas e assumem um compromisso de cuidado mútuo.

\subsubsection{Elementos do "Eu" de Maria apresentados no Desenho}

Mediante os procedimentos realizados com a intenção de trabalhar o eu corporal, Maria apresentou traços elaborados da formação do seu corpo (Desenho III). No seu autorretrato, Maria apresentou seus membros inferiores definidos, olhos nítidos, pintura na face e imagem colorida. Após terminar o desenho Maria, correndo, foi até a mesa da professora e disse:

- Tia terminei meu desenho. Olha como ele ficou incrível! Desenhei todas as partes do meu corpo, desenhei meu rosto, com olhos, boca, nariz, cílios, bochecha... no cabelo tem uma tiara. Me desenhei bem colorida: estou de uniforme e nele tem o nome do meu colégio. Desenhei meus braços, pernas, pés e mãos; não faltou nada.

Desenho III - Maria na representação do seu próprio corpo

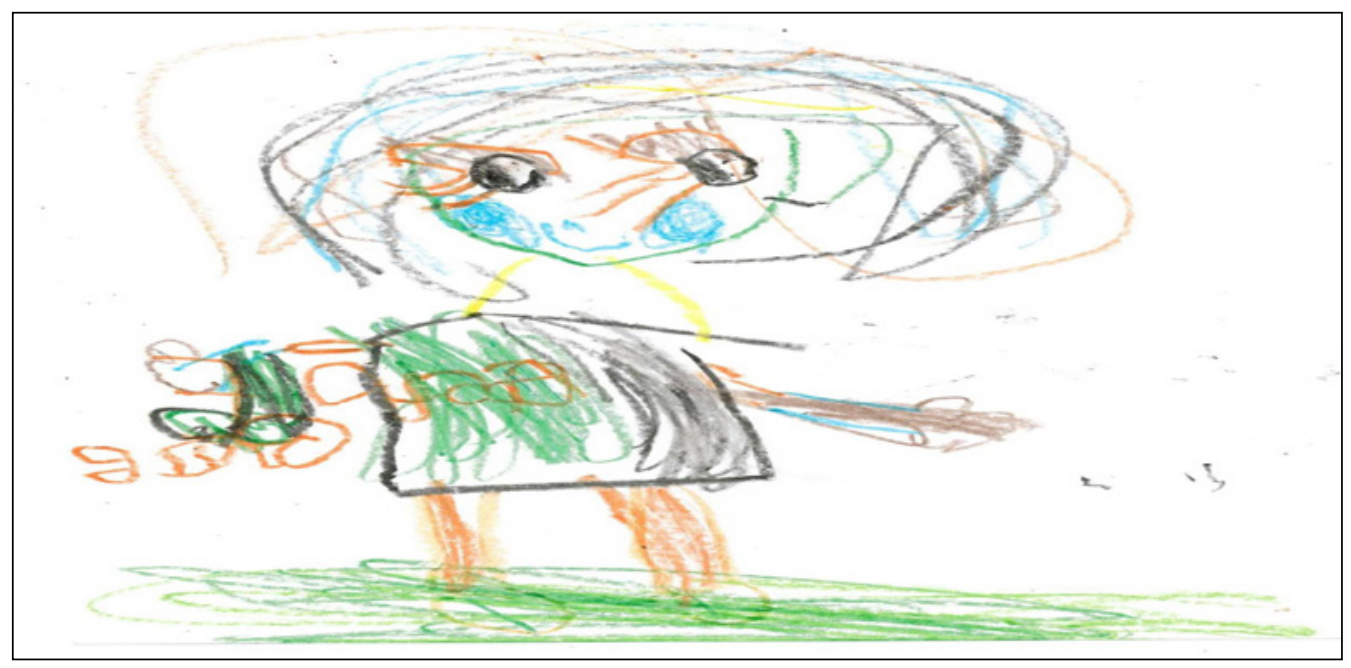

No momento em que foi trabalhado o autorretrato, ela demonstrou suas impressões e relatou o seu reconhecimento como um ser de maneira espontânea. Maria representou 
elementos constituintes de seu contexto social, histórico e cultural. Para Natividade, Coutinho e Zanella (2008) o desenho parece mesmo pertencente ao mundo da criança, parece coisa de infância sendo possível encontrar nos desenhos um mundo fantástico ou fantasioso de expressão infantil. Além desse mundo rico de imaginação que o desenho comunica, as autoras salientam que - por ser uma forma de linguagem - o ato de desenhar tem papel relevante para o desenvolvimento da capacidade cognitiva e semiótica, da criatividade e da expressão das emoções (Desenho IV).

Desenho IV - Maria no Shopping

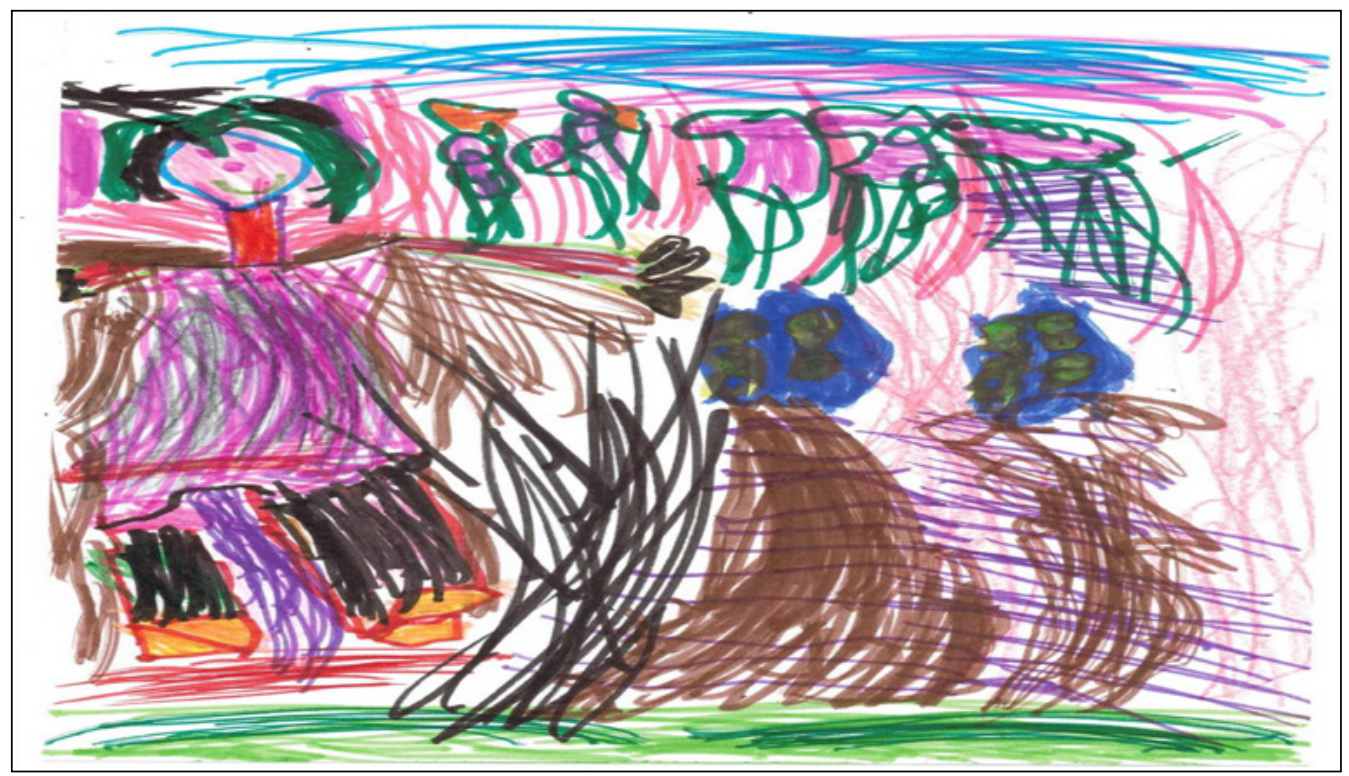

Um dos elementos presentes na sociedade capitalista é o shopping, espaço que marcou o desenho de Maria. Nesse local, ela se autorrepresentou com ornamentaria colorida, de vestido e maquiagem. Quando Maria foi questionada sobre o que era o seu desenho, ela respondeu: "Sou eu tia, passeando no shopping. Eu estava 'inclivel"'.

É assim que Maria se vê: alegre, com roupas possivelmente na moda e sapatos na cor laranja, elementos marcantes numa sociedade capitalista, onde as crianças são estimuladas a consumir. Por outro lado, Maria demonstrou seu lado infantil, usando sua imaginação com o desenho de duas árvores com almôndegas, que - na sua descrição - são deliciosas. Assim, observa-se a influência do seu contexto familiar, social, cultural e econômico, ao relatar-se num passeio no shopping, fazendo compras, bem-vestida e com sapatos.

A partir das fases do desenho propostas por Piaget, os desenhos de Maria podem ser situados no pré-esquematismo. Conforme Alexandroff (2010), faz parte da segunda metade da etapa pré-operatória até os sete anos quando ocorre a relação entre desenho, pensamento e realidade; porém, é possível verificar a relação entre os elementos dos 
desenhos de Maria (quando representou elementos de seu contexto familiar e escolar) e a constituição do seu eu, podendo situá-los na etapa do pré-esquematismo.

$\mathrm{Na}$ perspectiva vygotskyana, os desenhos de Maria demonstram elementos da etapa simbólica. Essa fase é dos conhecidos bonecos "cabeça-pés" que representam, de modo resumido, a figura humana. Trata-se da etapa na qual a visão do sujeito encontrase totalmente subordinada ao seu aparato dinâmico-táctil (VYGOTSKY, 1982). Esta etapa é descrita como o momento em que as crianças desenham os objetos "de memória" sem aparente preocupação com fidelidade à coisa representada. As crianças desenham o que já sabem sobre os objetos que buscam representar procurando destacar-lhes apenas os traços que julgam mais importantes (VYGOTSKY, 1982).

A cada desenho que a criança realiza, o jogo simbólico passa a ser uma necessidade e o ato de desenhar representa a exteriorização de uma ação que também representa uma etapa da construção de seu pensamento e, consequentemente, possibilita a aprendizagem e o desenvolvimento (PILLAR, 1996). Quanto à produção do desenho de Maria, ele representou o estágio da atividade simbólica, já que ela criou representações e categorias de objetos explorando as suas características gerais, incluindo formas, cores e qualidades espaciais.

\section{2 (Cri)ação e análises do desenho do Davi}

Davi, de cor branca, no decorrer do estudo tinha cinco anos e dois meses de idade, com $1,22 \mathrm{~cm}$ de altura e $24 \mathrm{~kg}$, de classe social média: seu pai é médico e a mãe é psicóloga. Sua família é constituída pelo seu pai, mãe e irmãos.

\subsubsection{Davi em seu Contexto Educativo}

Davi estuda no mesmo colégio desde que tinha um ano e meio de idade; iniciou no maternal no período integral. Além das atividades de sala de aula, participa de outras aulas como a de educação física, dança recreativa, inglês e leitura. A sua adaptação escolar - conforme descrição da professora - ocorreu sem maiores problemas: ele é comunicativo com colegas e funcionários, demonstra satisfação com as atividades que envolvam movimento com o corpo, como jogar futebol e dançar. Nas brincadeiras, interage com as crianças e tem amizade com colegas da mesma idade.

Também se envolve nas brincadeiras de acoplagem e jogos de construção imaginário. Demonstra preferência por jogos com blocos lógicos, quebra-cabeça, animais e nas brincadeiras de faz-de-conta prefere ser o papai. A riqueza na organização do espaço em termos de materiais desperta o seu interesse, é participativo e curioso nas atividades pedagógicas propostas na sala. Mantém atenção nas atividades realizadas, incluindo as palavras novas e situações desafiadoras ao seu cotidiano. 
No momento da rodinha de conversa, troca ideias e dá opiniões sobre os assuntos abordados, interagindo durante as atividades, a exemplo do momento da história sobre a qual, após a contação, faz questionamentos. Além disso, demonstra interesse pelos sentimentos dos colegas e carinho por eles, respeita regras e os combinados da turma.

Os desenhos de Davi apresentam, geralmente, elementos significativos, ao representar a temática escola. Durante a sua representação gráfica, o menino relatava o que estava construindo (Desenho V).

Desenho V - Davi no contexto escolar

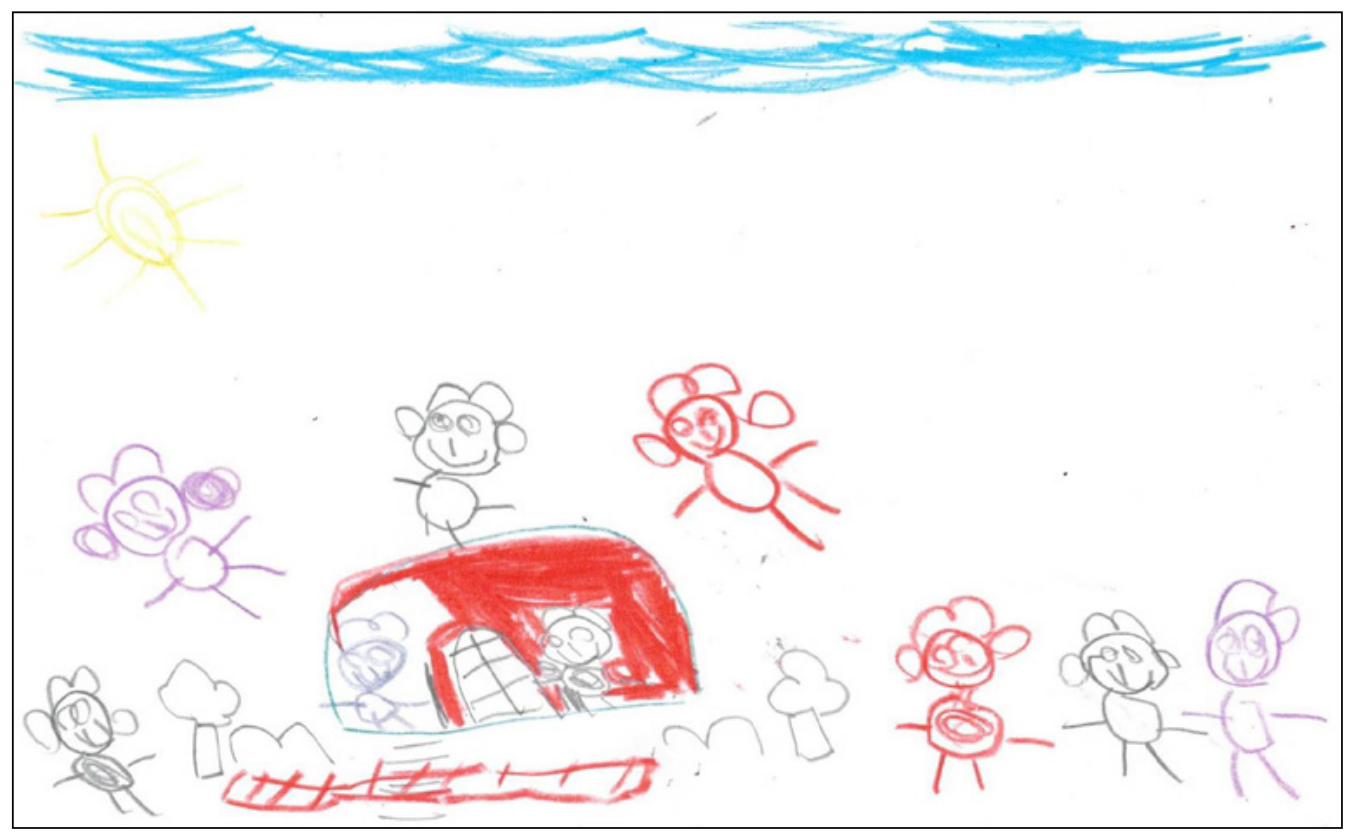

Davi representou o seu contexto escolar: em frente da escola representou a escada de vermelho, ele aparece em frente, juntamente, com sua professora. Desenhou os colegas de sala, alguns voando. Quando foi questionado sobre isso, respondeu que queria desenhar todos os amigos preferidos. Também, na imagem aparece o céu e as nuvens.

Em suas explicações Davi disse "que a escola é onde aprendemos um montão de coisas, que é legal estudar, e na escola aprendemos a desenhar, brincar, pintar, contar, dançar e histórias diferentes". A partir de Oliveira (2003) sugere-se que Davi expressa as suas emoções e que apresenta, no seu desenho, todos os elementos mais característicos do objeto, independente da posição que eles ocupem no espaço real. A expressão do desenho dele é uma manifestação da totalidade cognitiva e afetiva, comungando das ideias de Oliveira (2003), que considera que quanto mais a criança confia em si e no meio, mais ela se arrisca a criar e a se envolver com o que faz. Davi apresentou detalhes, com grande riqueza na elaboração e organização. 


\subsubsection{Davi nos Aspectos Familiares}

O desenho estabelece a ligação entre o objeto e a imaginação, entre a realidade e seu sonho, entre o universo individual e o universo social (GULLAR, 1982). É interessante observar que Davi, neste desenho, representou primeiramente a sua mãe, seguida de seu pai, na sequência ele e, por último, o irmão (Desenho VI).

Desenho VI - Davi e sua família

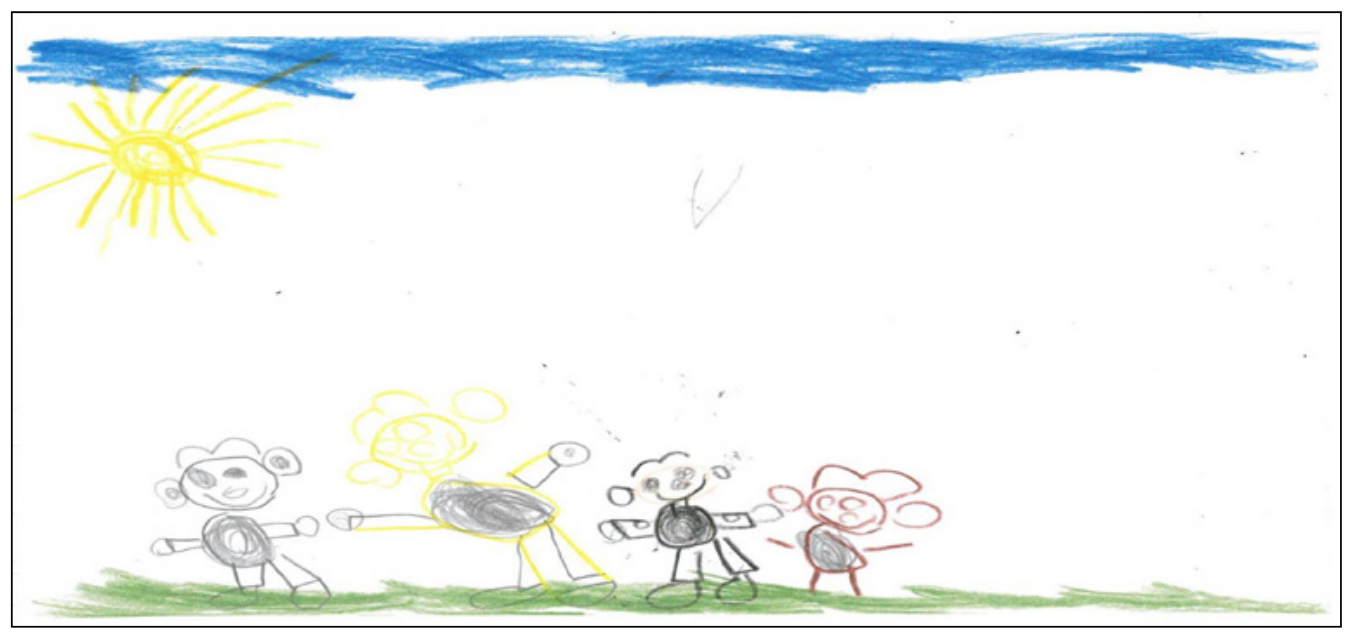

Davi já sabe quem são os membros que compõem sua família, desenhando-os harmoniosamente, com destaque para a figura do seu pai, que é o maior de sua casa, assim estando presentes elementos e representação do mundo familiar. Os desenhos são representações de uma maneira de estar no mundo, de se comunicar, de contar o que não se consegue transmitir por meio de palavras, o que acontece tanto com as crianças como com os adultos (RABELLO, 2013). Na fase inicial do desenho, a criança fala muito pouco, não consegue expressar o que sente, independentemente de ser algo agradável ou não. É lógico que também traz fatos que estão no seu consciente, uma situação gostosa ou mesmo algo que viveu (DI LEO, 1985). Davi representa conscientemente sua família, expressando as sutilezas do seu intelecto e da sua afetividade.

Davi usou todo o espaço do papel, preenchendo com detalhes e colorindo sua família. Davi - em um de seus relatos - relatou como o brincar é um elemento importante e presente na sua relação familiar: "tia, você sabia que a mamãe sabe brincar de videogame comigo?" Outros elementos do seu cotidiano familiar foram descritos: "Tia, a mamãe estuda igual eu, e o papai trabalha, e quando eles não estão, a vovó fica com a gente". Tal aspecto demonstrou o cuidado dos membros da família com Davi. 


\subsubsection{Elementos constituintes do "Eu” de Davi presentes no Desenho}

Davi, desenhando o seu eu, apresentou traços elaborados do seu esquema corporal (Desenho VII). Durante a construção do desenho, ele comunicava aos amigos o que estava desenhando e expressou que: "primeiro desenhei todas as partes do meu corpo, desenhei meu rosto, com olhos, boca, nariz. Me desenhei bem colorido, desenhei meus braços, pernas, pés e mãos, não faltou nada".

Desenho VII - Representação do eu de Davi

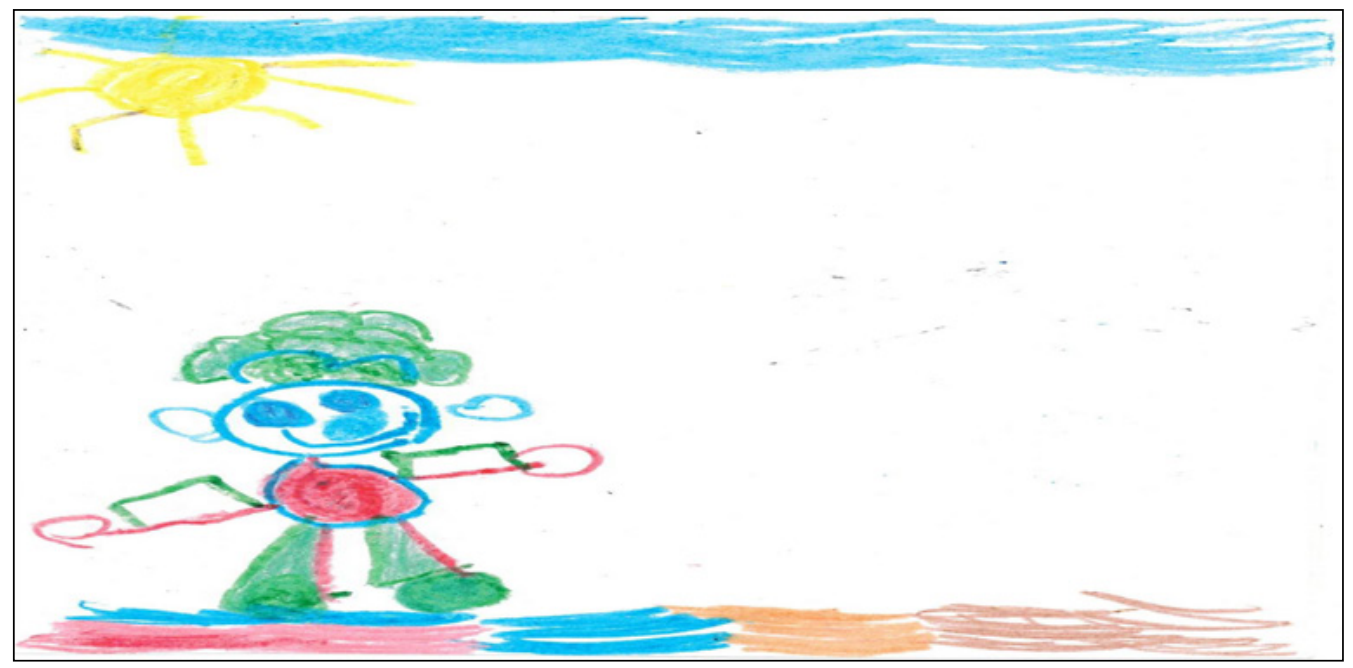

Os desenhos tornam-se enriquecidos por explicações posteriores, adquirindo características que se desenvolvem junto com uma fase automática da justaposição gráfica e reprodução em série de elementos gráficos antes isolados (VIEIRA, 2007). A partir das falas e do desenho de Davi, a sua imagem corporal demonstra a forma que ele se percebe e representa o próprio corpo: é a sua imagem mental.

A representação do esquema corporal é carregada de experiências pessoais que passam por constantes transformações: no plano subjetivo envolve o autoconceito, os sentimentos e as emoções. O corpo de Davi é apresentado com a especificação dos membros de seu corpo: cabeça, tronco, pernas, pés, braços, mãos, olho, boca, nariz, orelhas, cabelo e dedos (Desenho VIII), o que sugere o reconhecimento e identificação dos membros e elementos físicos constituintes do seu esquema corporal. 
Desenho VIII - Riqueza de detalhes no desenho do eu de Davi

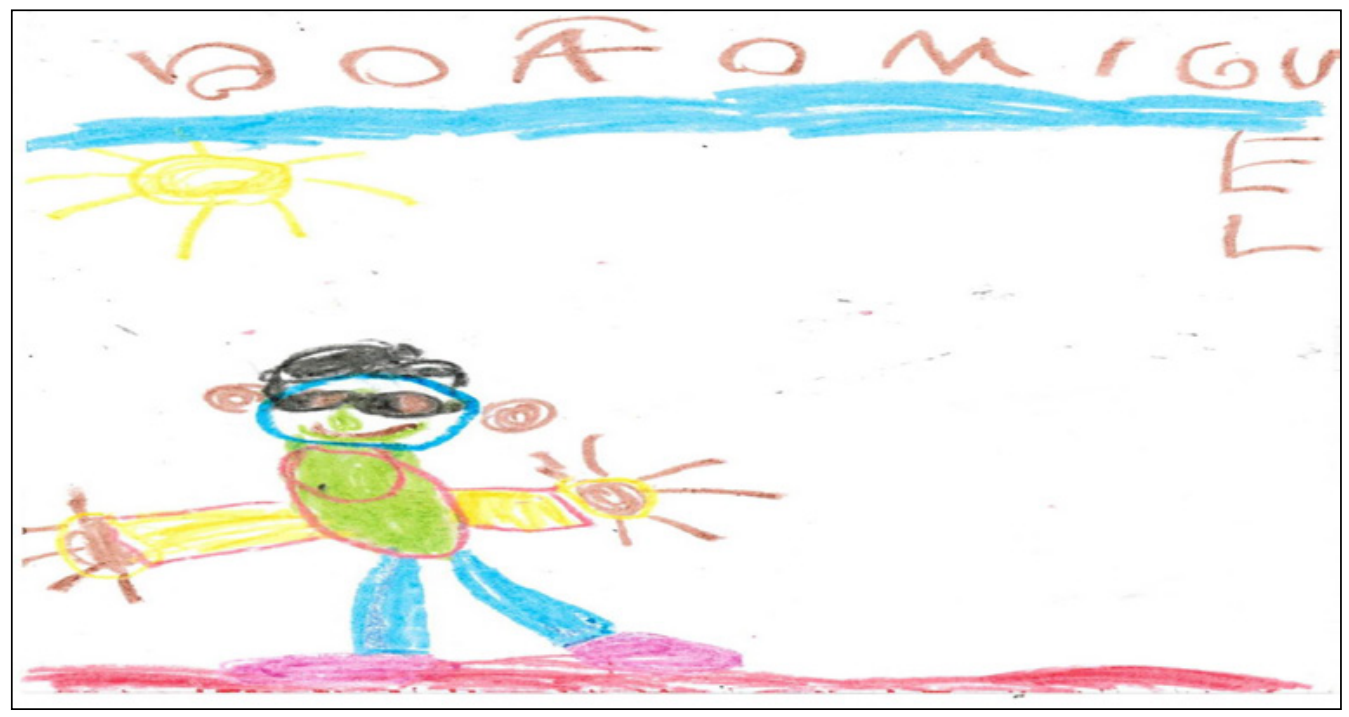

Cada cultura possui saberes, códigos e valores próprios que condicionam os sistemas de comunicação. O desenho de cada período histórico é condicionado por aquilo que em determinado momento é considerado verdadeiro e digno de importância (ZOPELARI, 2007). E assim acontece com nossas crianças que ainda não conhecem a simbologia das letras, mas expressam seus sentimentos por meio de riscos, rabiscos e mais tarde o desenho propriamente dito (SIO, 2005).

Observa-se nos desenhos VII e VIII de Davi a mudança nos seus detalhes, a exemplo das mãos, mas em ambos ele desenhou o seu autorretrato colorido demonstrando elementos do seu corpo, com imaginação e elementos de sua realidade. Quanto a isso, Vieira (2007) afirma que os grafismos começam a ganhar elementos múltiplos, sendo acompanhados de elementos justapostos, quando ocorre não só o aperfeiçoamento do grafismo, mas também da explicação.

O desenho que primeiramente era realizado pelo prazer de desenhar, num contínuo processo de aperfeiçoamento dos traçados pela criança, em momentos seguintes desperta pensamentos novos, uma vez que a criança começa a perceber certos "erros" que comete ao produzir graficamente (VIEIRA, 2007). Assim, a partir da perspectiva vygostskyana, é possível situar o desenho do Davi na fase simbólico-formalista, uma vez que ele demonstrou a elaboração de traços e as formas, com um maior número de relações entre o todo e suas partes.

\section{CONSIDERAÇÕES FINAIS}

Os desenhos das crianças Maria e Davi demonstraram elementos de seu contexto social e cultural. Por considerar o desenho como um passo para a escrita, por meio 
do qual as crianças vão delineando seus traços até a aquisição da linguagem escrita, percebe-se que isso está presente principalmente no desenho de Davi, uma vez que ele escreveu seu nome. Os desenhos dessas crianças não foram somente elementos lúdicos, mas sim instrumentos de seu processo de aprendizagem e desenvolvimento.

A descrição e a (cri) ação dessas duas crianças, por intermédio dos procedimentos de ensino denominados de Metodologia do Desenho, um dos elementos constituintes da prática pedagógica, evidenciaram que os pedagogos podem utilizar o desenho na sua práxis. Além disso, este estudo contribui com o repensar da ação pedagógica e a inclusão do desenho como elemento do processo educativo, uma vez que, durante as atividades as crianças demonstraram interesse, entraram no seu mundo imaginário e formaram novos esquemas dos temas trabalhados: noção do esquema corporal, autorretrato, contexto escolar e família.

Quando o professor se propõe a trabalhar essas temáticas, aplicando a metodologia do desenho, simultaneamente as habilidades de coordenação motora, equilíbrio, raciocínio lógico, linguagem oral e escrita estão em evidência no processo desenvolvimento e aprendizagem. Através do desenho o professor obtém informações sobre o desenvolvimento, levanta hipóteses e percebe características afetivas, emocionais, intelectuais, perceptivas e psicomotoras da criança.

A criança que se expressa de forma livre confia mais em si e no meio, arriscando-se a criar e a se envolver com o que faz, tornando as atividades prazerosas e conseguindo identificar-se nas suas representações. Em síntese, a partir de Vygotsky que considera o desenvolvimento cognitivo "de fora para dentro", os instrumentos utilizados na Metodologia do Desenho, a exemplo de história dos ursos, imagens de revistas, livros, fotografias, fantoches, bonecos articuladores entre outros foram mediadores da aprendizagem e do desenvolvimento. $\mathrm{E}$ os conhecimentos que as crianças possuíam do seu cotidiano foram transformados em conceitos científicos.

Por outro lado, a partir de Piaget que trabalha o desenvolvimento intelectual, "de dentro para fora", as crianças Maria e Davi já possuíam alguns esquemas de família relacionados ao cuidado, proximidade, convivência; do autorretrato - já que as crianças conseguiam se ver e desenhar os membros do seu corpo -; e de escola como um espaço do cuidar, brincar, ler e escrever. Piaget considera que o desenvolvimento cognitivo e o amadurecimento das estruturas lógicas (esquemas mentais) decorrem de processos endógenos de equilíbrio que precedem e limitam a aprendizagem (PALANGANA, 2001). Nesse sentido, é possível sugerir que as crianças Maria e Davi, já tinham estruturas mentais e o desenvolvimento físico, favorecedoras da ampliação dos esquemas de família, escola e do eu, sendo a metodologia do desenho facilitadora da aprendizagem.

Quanto às fases do desenho na perspectiva piagetiana, Maria foi situada no préesquematismo e na vygotskyana na etapa simbólica, enquanto Davi foi situado na fase simbólico-formalista de Piaget com a demonstração de maior elaboração dos traços e formas no desenho infantil. 


\section{REFERÊNCIAS}

ALEXANDROFF, M. C.. Os caminhos paralelos do desenvolvimento do desenho e da escrita. Constr. psicopedag. [online]. vol.18, n.17, 20110. Disponível em: <http://pepsic. bvsalud.org/scielo.php?script=sci_arttext\&pid=S1415-69542010000200003\&lng=pt\&nrm=i so>. ISSN 1415-6954.

DI LEO, J. H. A interpretação do desenho infantil. Porto Alegre:Artes Médicas, 1985.

GULLAR, F.. Sobre arte. São Paulo: Palavra e Imagem, 1982.

LIMA, M. M. S. A cidade e a criança. São Paulo: Nobel, 1989.

LOPES, L.O. O processo de significação do desenho infantil. Trabalho de Conclusão de Curso de Pedagogia, Universidade Estadual de Maringá, 2010. Disponível em: <http://www. crc.uem.br/pedagogia/documentos/larissa_lopes.pdf>. Acesso em 08 dez. 2014.

MEREDIEU, F.. O desenho infantil. 10 ed. São Paulo: Cultrix, 2004.

MOREIRA, A. A. A.. O espaço do desenho: a educação do educador. São Paulo, SP: Loyola, 1995.

NATIVIDADE, M.R.; COUTINHO, M. C.; ZANELLA, A. V. Desenho na pesquisa com crianças: análise na perspectiva histórico-cultural. Contextos Clínicos, v. 1, n. 1, jan.jun. p.9-18, 2008.

OLIVEIRA, G.C. Psicomotricidade: educação e reeducação num enfoque psicopedagógico. Petrópolis, RJ, vozes, 2003.

PIAGET, J.. Seis estudos de Psicologia. Rio de Janeiro: Forense, 1969.

. A formação do símbolo na criança. Rio de janeiro: Zahar, 1978.

. Psicologia e pedagogia. Rio de Janeiro: Forense, 1970.

. Psicologia e epistemologia: por uma teoria do conhecimento. Rio de Janeiro:

Forense, 1973.

PALANGANA, I. C. Desenvolvimento e aprendizagem em Piaget e Vygotsky: a relevância do social. 5. ed. Editora: Summus, 2001.

PILLAR, A D. Desenho e escrita como sistemas de representação. Porto Alegre: Artes Médicas, 1996.

RABELLO N.. O desenho infantil: entenda como a criança se comunica por meio de traços e cores. Rio de Janeiro: Wak Editora, 2013.

SANTOS. S. Estudo de caso - A interpretação do desenho infantil. Educareeducare Ano XV - no 1 - II Série, 2013. Disponível em:

educare.ese.ipcb.pt/index.php/educare/article/download/30/9 Acesso: 2 jul. 2015.

SIMAS, D.L. Riscos e rabiscos: a contribuição do desenho infantil para a alfabetização. 2011, 48 f. Trabalho de Conclusão de Curso (Graduação), Universidade do Estado da Bahia, 
Salvador, 2011 Disponível em: <http://www.uneb.br/salvador/dedc/files/2011/05/MonografiaDaiana-Leao-Simas.pdf>. Acesso em 08 dez. 2014.

SIO, R.T.G. A importância do desenho no desenvolvimento infantil crianças de 02 a 07 anos. IV Educere, II Congresso Nacional na Área de Educação, PUCPR, 2004. Disponível em: www2.pucpr.br/reol/index.php/dialogo?dd99=pdf\&dd1=1840 Acesso: mai. de 2015.

VIEIRA, F.V. o processo de significação do desenho infantil. Trabalho de Conclusão de Curso de Licenciatura em Pedagogia. Universidade Federal de São Carlos, São Carlos, 2007. Disponível em: <http://www.pedagogia.ufscar.br/documentos/arquivos/tcc-2004/o-processode-significacao-do-desenho-infantil>. Acesso em: 22 mar 2015.

VYGOSTKY, L.S. A formação social da mente. São Paulo: Martins Fontes, 1989.

. Pensamento e linguagem. São Paulo, Martins Fontes, 2003.

. La imaginación y el arte en la infância. México, Hispânicas, 1987.

ZOPELARI, L.F.P. Desenho: uma forma e desenvolvimento infantil. Faculdade de Educação São Luis, Jaboticabal-SP, 2007. Disponível em: <http://www.portaldosprofessores. ufscar.br/biblioteca/112/artigo_desenho_livre_lauri_2_1_.pdf >. Acesso em: 12 dez. 2014. 